\title{
ARTICLE
}

\section{Beta dose rate measurements with an end-window GM survey meter in environments contaminated by the Fukushima Daiichi nuclear accident}

\author{
Norio Tsujimura* and Tadayoshi Yoshida \\ Japan Atomic Energy Agency, 4-33 Muramatsu, Tokai-mura, Naka-gun, Ibaraki-ken, 319-1194, Japan
}

\begin{abstract}
The authors made calibration of an end-window Geiger Müller (GM) survey meter in terms of the beta dose rate and applied it to measurements of the beta dose rate in the environments contaminated by the Fukushima Daiichi nuclear accident. The range of validity of the calibration factors to be applied to the GM probe was verified (1) by the measurement of contaminated soil samples removed from the crippled nuclear power plant site and (2) the environmental field survey at Fukushima city.
\end{abstract}

Keywords: end-window Geiger Müller (GM) survey meter; beta dose rate; calibration; Fukushima Daiichi nuclear accident

\section{Introduction}

The accident at the Fukushima Daiichi nuclear power plant resulted in a substantial release of radionuclides into the atmosphere, leading to extensive contamination in the environment. Throughout the emergency radiological monitoring, air ionization chamber or scintillation survey meters were generally used for measurement of the gamma-ray dose equivalent rates, whereas end-window Geiger-Müller (GM) probes were exclusively used for beta-particle measurement in surface contamination surveys. Typically, surface radioactivity is measured to provide information on whether further action such as decontamination should be taken; however, in a highly contaminated situation, the direct measurement of the external beta dose rates from the contamination is preferred since it allows the magnitude of the radiation hazard to be estimated [1].

For this reason, the authors initiated the present study to calibrate an end-window GM probe in terms of the beta dose rate instead of a standard calibration in units of $\mathrm{Bq} / \mathrm{cm}^{2}$. This paper describes the calibration procedures for the GM probe and the results of the beta dose rate measurements performed in the actual environments contaminated by the Fukushima Daiichi nuclear accident.

\section{Instruments}

\subsection{End-window GM surface contamination survey meter}

The GM surface contamination survey meter used in

*Corresponding author. Email: tsujimura.norio@jaea.go.jp this study is an Aloka Model TGS-113, which consists of a hand-held GM probe and a rectangular count rate meter unit with a carrying handle and probe clip. This model was chosen because the Model TGS series of contamination survey meters can be found in all facilities where radioactive materials are used. The probe is an end-window GM tube that has a thin mica window of a thickness of $\sim 2.5 \mathrm{mg} / \mathrm{cm}^{2}$ and a diameter of $50 \mathrm{~mm}$. The active area $\left(20 \mathrm{~cm}^{2}\right)$ is protected by a punched mesh stainless steel screen with an open area of $85 \%$. The overall length of the probe is $150 \mathrm{~mm}$. Instrument efficiency is $\sim 40 \%$ for beta particles from ${ }^{36} \mathrm{Cl}$ (maximum beta energy $\mathrm{E}_{\beta \max }=0.71 \mathrm{MeV}$ ); thereby a reading of 1000 counts per minute $(\mathrm{cpm})$ corresponds to $\sim 2 \mathrm{~Bq} / \mathrm{cm}^{2}$. All models of the TGS series are of an essentially identical construction and beta counting efficiency, with only minor model-dependent variations.

An end-window GM tube has literally a window, which beta particles can penetrate, on one end of the metal tube. The window inevitably imparts strong directional properties; that is, the recessed sensitive volume is shielded by the side wall from beta particles coming from large angles. This suggests that the end-window probe provide significantly low counts to widely distributed beta sources exceeding the size of the window. Indeed, an end-window GM counter, calibrated with a parallel-like beam produced by a distant point source, will not give accurate surface dose measurements from a widely distributed beta source.

\subsection{Reference beta dose rate meter}

An Oyo-Giken AE-133B air-filled ionization chamber survey meter was used for dual purposes: as a comparative instrument with an end-window GM probe 
and as a reference beta dose-measuring instrument. The AE-133B has a flat cylindrical ionization chamber with a window diameter of $100 \mathrm{~mm}$, a window thickness of 7 $\mathrm{mg} / \mathrm{cm}^{2}$, and an effective thickness of the collecting volume of $\sim 1.2 \mathrm{mg} / \mathrm{cm}^{2}$. The front face of the window is flush with the side wall edge. Such a chamber construction imparts good energy and angular response in the beta dose measurement, being markedly in contrast to that of an end-window GM probe. The prior calibration of the AE-133B with standard beta calibration sources presented nearly energy- and angular-independent responses for ${ }^{204} \mathrm{Tl}$ and ${ }^{90} \mathrm{Sr}-{ }^{90} \mathrm{Y}$, with a slight under-response $(\sim 20 \%)$ for ${ }^{147} \mathrm{Pm}$.

\section{Calibration}

\subsection{Methods}

Generally, end-window GM probes with a count rate scale do not have the beta detection characteristics needed for accurate beta dosimetry. Therefore, we studied calibration factors that allow the readings of the TGS-113 GM survey meter to be converted directly into an accurate beta dose rate. The study was performed in a manner similar to that described by Coleman [2], in which calibration of a pancake GM probe was made under two different beta irradiation conditions.

Five beta calibration sources were used: three from Amersham-Buchler $-{ }^{147} \mathrm{Pm}$ (nominal activity of 518 $\mathrm{MBq}),{ }^{204} \mathrm{Tl}(18.5 \mathrm{MBq})$, and ${ }^{90} \mathrm{Sr}-{ }^{90} \mathrm{Y}$ (74 MBq) — and two from Japan Radioisotope Association (JRIA) - ${ }^{204} \mathrm{Tl}$ (37 kBq) and ${ }^{90} \mathrm{Sr}-{ }^{90} \mathrm{Y}(37 \mathrm{kBq})$. The former three were encapsulated sources with a thin window and a thick backing, whereas the latter two were thin film sources in which the radioactive materials were fixed between $\sim 1$ $\mathrm{mg} / \mathrm{cm}^{2}$ aluminized polyester films. These sources covered a range of maximum beta energies from 0.22 $\mathrm{MeV}\left({ }^{147} \mathrm{Pm}\right)$ through $0.77 \mathrm{MeV}\left({ }^{204} \mathrm{Tl}\right)$ to $2.3 \mathrm{MeV}$ $\left({ }^{90} \mathrm{Y}\right)$.

\subsubsection{Beta rays: parallel-like beam source}

Parallel-like beta beam fields were produced by three different point sources: ${ }^{147} \mathrm{Pm},{ }^{204} \mathrm{Tl}$, and ${ }^{90} \mathrm{Sr}-{ }^{90} \mathrm{Y}$. The first two sources are of the Amersham-Buchler beta calibration standard system Type 1 , and the reference dose rate (the directional dose equivalent at a depth of 7 $\mathrm{mg} / \mathrm{cm}^{2}$, in units of $\mathrm{Sv} / \mathrm{h}$ ) of the beta field delivered downstream from each source mounted on the support jig was determined by the primary standard laboratory's transfer instrument. The JRIA $37 \mathrm{kBq}{ }^{90} \mathrm{Sr}-{ }^{90} \mathrm{Y}$ source was used here instead of the Amersham-Buchler ${ }^{90} \mathrm{Sr}-{ }^{90} \mathrm{Y}$ source since the GM tube was completely saturated by the latter source of strong activity. The reference dose rate delivered by the $37 \mathrm{kBq}{ }^{90} \mathrm{Sr}^{90}{ }^{90} \mathrm{Y}$ source was measured by the AE-133B ionization chamber, which was calibrated with the Amersham-Buchler ${ }^{90} \mathrm{Sr}-{ }^{90} \mathrm{Y}$ source. The TGS-113 GM probe was exposed under parallel-like beam conditions at distances of $15 \mathrm{~cm}\left({ }^{147} \mathrm{Pm}\right), 30 \mathrm{~cm}\left({ }^{204} \mathrm{Tl}\right)$, and $12 \mathrm{~cm}$ $\left({ }^{90} \mathrm{Sr}-{ }^{90} \mathrm{Y}\right)$ with the window facing the source perpendicular to the beam axis.

\subsubsection{Beta rays: distributed source}

A point $37 \mathrm{kBq}{ }^{204} \mathrm{Tl}$ source, manufactured by the JRIA, was used in a traverse technique [1] to predict the response of the GM probe to a uniformly distributed source. The GM probe was held with the window $5 \mathrm{~cm}$ above the wooden lab bench, on which the source was moved along a line starting directly under the window, and then a series of measurement was conducted at each source location. Each measurement was integrated over the circular area including all the source positions and then compared with the corresponding beta dose rate calculated by the computer code VARSKIN [3]. The code calculated the beta doses to the sensitive areas of the two detectors, $20 \mathrm{~cm}^{2}$ for the TGS-113 and $50 \mathrm{~cm}^{2}$ for the AE-133B, with a $5 \mathrm{~cm}$ air gap above the center of uniformly distributed ${ }^{204} \mathrm{Tl}$ flat disc sources.

In all measurements, the output of the GM probe was connected to a scaler, accumulated, and then compared with the reference beta dose rate to yield the response in units of cpm per $\mathrm{nSv} / \mathrm{h}$. Dead time correction was not made since all measurements was made below $5 \times 10^{4}$ cpm, at which the pile-up could be neglected.

\subsubsection{Gamma-ray sensitivity}

GM tubes are also sensitive to gamma rays, although being very low sensitivity. Therefore, we checked the response of the TGS-113 GM probe to photons from encapsulated sources of ${ }^{137} \mathrm{Cs}-{ }^{137 m} \mathrm{Ba}$ and ${ }^{133} \mathrm{Ba} ;{ }^{133} \mathrm{Ba}$ has energy lines similar to those of ${ }^{131} \mathrm{I}$. The irradiations were made for the probe both with and without an acrylic resin cap, which provided discrimination capability in beta + gamma mixed fields.

\subsection{Calibration results}

Figure 1 shows the dose rate response of the end-window GM probe under parallel-like beam conditions plotted as a function of the maximum beta energy. The response exhibits a clear energy-dependence, directly proportional to the maximum beta energy in a relatively linear manner. When normalized to the response to ${ }^{204} \mathrm{Tl}$, the low-energy beta particles from ${ }^{147} \mathrm{Pm}$ yielded a $24 \%$ low response, whereas the higher energy beta source of ${ }^{90} \mathrm{Sr}-{ }^{90} \mathrm{Y}$ gave a higher response by $20 \%$. Given the fact that most of the beta dose rates originated from ${ }^{132} \mathrm{I}$ (daughter of ${ }^{132} \mathrm{Te}$ ) during the initial weeks after the accident and were followed by ${ }^{131} \mathrm{I}$ [4] and later by ${ }^{134} \mathrm{Cs}$ and ${ }^{137} \mathrm{Cs}$, the desirable beta monitoring range was considered to be in the range bounded by ${ }^{131} \mathrm{I}\left(\mathrm{E}_{\beta \max }=\right.$ $0.61 \mathrm{MeV})$ and ${ }^{132} \mathrm{I}\left(\mathrm{E}_{\beta \max }=2.1 \mathrm{MeV}\right)$. This range approximately corresponds to that covered by ${ }^{204} \mathrm{Tl}$ and ${ }^{90} \mathrm{Sr}-{ }^{90} \mathrm{Y}$.

Figure 2 shows the geometry dependence of the relative response of the GM probe on a radius of the distributed ${ }^{204} \mathrm{Tl}$ source. Also plotted are the responses of the AE-133B chamber under the same source condition for comparison. The response of the GM probe 
monotonically decreased with increasing a radius, whereas that of the AE-133B showed a relatively small dependence. This result agreed with that expected from the differences in the construction details between the two detectors. The curve presented in Figure 2 was used to account for the source geometry correction for the end-window GM probe.

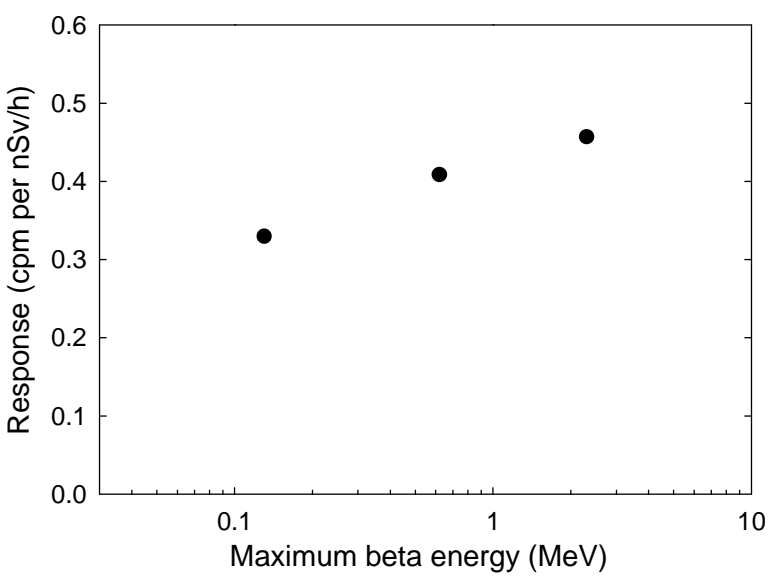

Figure 1. Beta dose rate response of a TGS-113 end-window GM probe for the parallel-like beam source. The data for ${ }^{90} \mathrm{Sr}-{ }^{90} \mathrm{Y}$ is plotted at $\mathrm{E}_{\beta \max }$ of $2.3 \mathrm{MeV}$, whereas the others for ${ }^{204} \mathrm{Tl}$ and ${ }^{147} \mathrm{Pm}$ are plotted at residual maximum energies of 0.62 and $0.13 \mathrm{MeV}$, respectively.

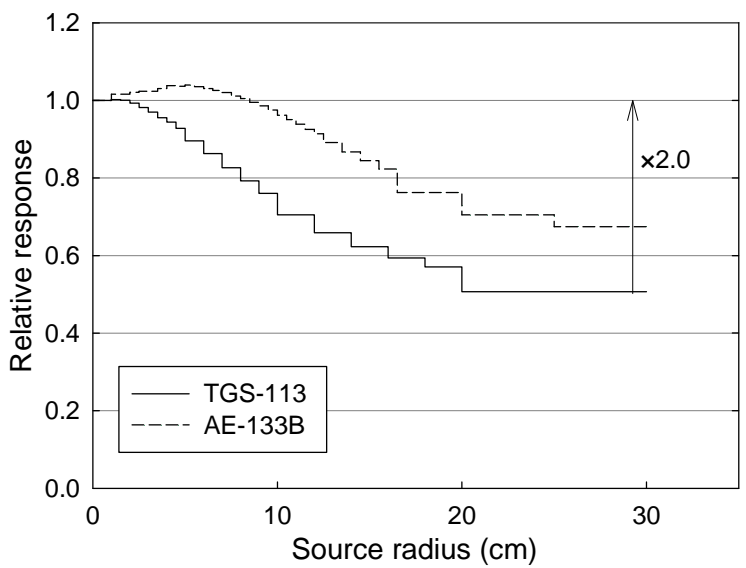

Figure 2. Relative response of a TGS-113 end-window GM probe and an AE-133B ionization chamber as a function of the radius for the simulated circular-distributed ${ }^{204} \mathrm{Tl}$ source. Data are normalized to unity at a radius of $0 \mathrm{~cm}$.

From the results described above, we determined calibration factors for measuring the beta dose rate using the TGS-113 end-window GM probe. The beta dose rate, $H_{\beta}$, is derived by

$$
H_{\beta}=K_{\mathrm{E}} K_{\mathrm{G}}\left(C_{\mathrm{op}}-C_{\mathrm{cl}}\right)
$$

where $K_{\mathrm{E}}$ is the calibration factor; $K_{\mathrm{G}}$ is the geometry correction factor, either 1.0 for a distant point source (or "parallel-like" beam) or 2.0 for a distributed source (or "radial" beam); and $C_{\mathrm{op}}$ and $C_{\mathrm{cl}}$ are the count rates (cpm) of the GM probe without and with a resin cap, respectively. The $K_{\mathrm{E}}$ value, $2.4 \mathrm{nSv} / \mathrm{h}$ per cpm, was based on the response to ${ }^{204} \mathrm{Tl}$ under the beam geometry, selected as the most conservative factor for the expected beta energy range. The $K_{\mathrm{G}}$ values selected were intended to encompass any sizes of distributed sources. The uncertainty of the product of $K_{\mathrm{E}}$ and $K_{\mathrm{G}}$ was estimated to be less than $20 \%(\mathrm{k}=2)$. Additionally, the calibration factor of the GM probe to ${ }^{137} \mathrm{Cs}$ gamma rays of normal incidence into the window was $2.2 \mathrm{nSv} / \mathrm{h}$ per cpm despite the presence of a resin cap; the angular response dropped by $50 \%$ at $90^{\circ}$ from that at normal incidence. The response to ${ }^{133} \mathrm{Ba}$ was $\sim 80 \%$ of the ${ }^{137} \mathrm{Cs}$ gamma response.

\section{Beta dose rate measurement in environments}

\subsection{Contaminated soil samples taken from the Fukushima Daiichi nuclear power plant site}

Beta and gamma dose rates were measured at the surface of soil samples collected on 22-23 March 2011 at several locations within $1 \mathrm{~km}$ from reactor Units 1 and 2 at the Fukushima Daiichi nuclear power plant site [4]. The major radionuclides found in the soil samples at the time were ${ }^{129 \mathrm{~m}} \mathrm{Te},{ }^{132} \mathrm{Te}-{ }^{132} \mathrm{I},{ }^{131} \mathrm{I},{ }^{134} \mathrm{Cs},{ }^{137} \mathrm{Cs}^{137 \mathrm{~m}} \mathrm{Ba}$, etc. The measurements were performed twice, in April 2011 and October 2011. Each soil sample was packed into a 13-cm-diameter plastic container to a depth of $5 \mathrm{~cm}$. The entrance window of the TGS-113 GM probe was placed $5 \mathrm{~cm}$ above the soil sample. The reference dose rate was measured by the AE-133B ionization chamber under the same geometry. A part of the soil sample (\#6) was spread over a $27 \times 32 \mathrm{~cm}^{2}$ tray to a depth of $\sim 3 \mathrm{~mm}$, and additional measurement was also conducted at $5 \mathrm{~cm}$ above the soil.

Table 1 compares the beta dose rates evaluated with the two detectors. A resin filter cap was used to discriminate the gamma-ray components. The results revealed that the beta dose rate ranges evaluated by the TGS-113 GM probe are consistent with those from the AE-133B ionization chamber and that, for the distributed source (\#6'), the geometry correction factor of 2.0 provided better agreement. A small discrepancy of the beta dose rate for the sample of $\# 6^{\prime}$ is likely attributable to the surface roughness of the source, which increases the measurement uncertainty for wider sources.

\subsection{Field study at Fukushima city}

From 26 to 28 September 2011, a field study was carried out with portable survey instruments at 10 locations in Fukushima city. At each location, the measurements were made at 5 and $100 \mathrm{~cm}$ above the ground using the TGS-113 GM probe with the window facing the ground. The dose rates were anticipated to be extremely low for direct measurement using the AE-133 ionization chamber; therefore, an Aloka TCS-161 scintillation gamma survey meter was chosen to corroborate the data measured by the GM probe. The TCS-161 employs a $25 \mathrm{~mm} \phi \times 25 \mathrm{~mm} \mathrm{NaI(Tl)}$ crystal with a discrimination bias modulation (DBM) circuit, which adjusts the output pulses from the crystal so that 
Table 1. Comparison of the beta dose rate $(\mu \mathrm{Sv} / \mathrm{h})$, measured by the TGS-113 end-window GM probe and the AE-133B ionization chamber, at $5 \mathrm{~cm}$ above the surface of contaminated soil samples collected at the Fukushima Daiichi nuclear plant site.

\begin{tabular}{|c|c|c|c|c|c|c|c|c|}
\hline \multirow{2}{*}{ Instrument } & \multirow{2}{*}{$K_{\mathrm{G}}$} & \multicolumn{6}{|c|}{ Plastic container $(13 \mathrm{~cm} \phi)$} & \multirow{2}{*}{$\begin{array}{c}\text { Plastic tray } \\
\left(27 \times 32 \mathrm{~cm}^{2}\right) \\
\# 6\end{array}$} \\
\hline & & $\# 1^{\mathrm{a}}$ & \#2 & \#3 & \#4 & \#5 & \#6 & \\
\hline \multirow{2}{*}{ TGS-113 } & 1.0 & 14 & 39 & 72 & 1.8 & 14 & 28 & 48 \\
\hline & 2.0 & 28 & 78 & 140 & 3.6 & 28 & 56 & 96 \\
\hline AE-133B & - & 23 & 59 & 100 & 2.5 & 22 & 50 & 100 \\
\hline
\end{tabular}

${ }^{\mathrm{a}}$ Soil samples of \#1 to \#3 were collected at $750 \mathrm{~m}$ south-southwest, $500 \mathrm{~m}$ west-northwest, and $500 \mathrm{~m}$ north of the stack of Unit 1 on March 22-23, 2011, respectively. The measurement was made twice, on April 12, 2011 and October 20, 2011. In the latter measurement, the soil samples of $\# 1, \# 2$, and $\# 3$ are re-numbered $\# 4$, $\# 5$, and $\# 6$ ( $\# 6^{\prime}$ ), respectively.

Table 2. Measurement results of the beta and gamma dose rates $(\mu \mathrm{Sv} / \mathrm{h})$ in outdoor environments at Fukushima city.

\begin{tabular}{|c|c|c|c|c|c|c|c|c|c|}
\hline & \multirow{3}{*}{ Location } & \multirow{3}{*}{ Surface material } & \multicolumn{3}{|c|}{$100 \mathrm{~cm}$ height } & \multicolumn{4}{|c|}{$5 \mathrm{~cm}$ height } \\
\hline & & & \multirow{2}{*}{$\begin{array}{c}\mathrm{NaI} \\
H_{\gamma}\end{array}$} & \multicolumn{2}{|c|}{ GM } & \multirow{2}{*}{$\begin{array}{c}\mathrm{NaI} \\
H_{\gamma}\end{array}$} & \multicolumn{3}{|c|}{ GM } \\
\hline & & & & $H_{\gamma}{ }^{a}$ & $H_{\beta}$ & & $H_{\gamma}{ }^{a}$ & $H_{\beta}$ & $H_{\beta} / \mathrm{H}_{\gamma}$ \\
\hline 1 & Sidewalk & Interlocking concrete & 1.0 & 1.0 & $<0.1$ & 1.0 & 1.0 & 7.4 & 8 \\
\hline 2 & Park & Soil & 1.4 & 1.3 & $<0.1$ & 1.9 & 1.5 & 1.4 & 1 \\
\hline 3 & Bridge & Asphalt & 0.7 & 0.7 & 0.5 & 1.0 & 1.0 & 14 & 14 \\
\hline 4 & Parking lot & Asphalt & 1.0 & 1.0 & 0.7 & 1.4 & 1.5 & 14 & 9 \\
\hline 5 & Park & Soil & 1.8 & 1.5 & 0.2 & 1.3 & 1.3 & 0.3 & 0.3 \\
\hline 6 & Backyard & Soil + fallen leaves & 1.5 & 1.3 & 0.3 & 2.0 & 1.9 & 5.5 & 3 \\
\hline 7 & Parking lot & Asphalt & 0.4 & 0.4 & 0.4 & 0.8 & 0.6 & 5.5 & 10 \\
\hline 8 & Backyard & Soil & 0.4 & 0.4 & 0.2 & 0.5 & 0.4 & 0.4 & 1 \\
\hline 9 & Parking lot & Soil + gravel & 0.6 & 0.6 & 0.1 & 0.7 & 0.6 & 0.9 & 2 \\
\hline 10 & Park & Lawn & 0.6 & 0.6 & 0.1 & 0.7 & 0.7 & 0.8 & 1 \\
\hline
\end{tabular}

${ }^{a}$ The gamma dose equivalent rate, $H_{\gamma}$, was estimated by $C_{\mathrm{cl}} \times 2.2(\mathrm{nSv} / \mathrm{h}$ per $\mathrm{cpm})$ based on ${ }^{137} \mathrm{Cs}$ gamma calibration.

the height of the pulse should be proportional to the dose, and thus a rate of the biased pulses above a discrimination level directly indicates the dose rate. Both the instruments' readings were read on the analog display; therefore, a substantial amount of random errors was likely included in the measurement.

Table 2 summarizes the beta and gamma dose rates measured by the two detectors, along with the description of the locations and their surface conditions. For beta dosimetry with the GM probe, $K_{\mathrm{G}}=2.0$ was used in eq. (1). At $5 \mathrm{~cm}$ above the ground, the beta dose rates measured by the GM probe ranged from 0.3 to 14 $\mu \mathrm{Sv} / \mathrm{h}$, whereas the gamma dose rates were in the ranges of 0.4 to $1.9 \mu \mathrm{Sv} / \mathrm{h}$ for the $\mathrm{GM}$ probe and of 0.5 to 2 $\mu \mathrm{Sv} / \mathrm{h}$ for the $\mathrm{NaI}(\mathrm{Tl})$. The average beta dose rate of 5.0 $\mu \mathrm{Sv} / \mathrm{h}$ at $5 \mathrm{~cm}$ was reduced to $\sim 0.3 \mu \mathrm{Sv} / \mathrm{h}$ at $100 \mathrm{~cm}$ because of air attenuation, but the average gamma dose rate decreased by $\sim 30 \%$ in the same height range.

The beta-to-gamma dose rate ratio depended on the ground surface condition, ranging from 0.3 on soil to 14 on an asphalt surface. The dispersion of radionuclides into soil, even if it was thin, acts as a shield to beta particles and decreases the beta-to-gamma ratio. In contrast, the latter asphalt surface would provide relatively less self-absorption. The maximum beta-to-gamma ratio of 14 was observed at the middle of a bridge. This occurred because most beta particles came from a nearby surface, although the gamma rays of both terrestrial and fallout components were minimal on the water. The field study at Fukushima city demonstrated the usefulness of end-window GM probes for measuring the beta dose rate.

\section{Conclusion}

The authors calibrated an end-window GM surface contamination survey meter in terms of the beta dose rate and applied it to the measurement of the beta dose rate in the environments contaminated by the Fukushima Daiichi nuclear power plant accident. The range of validity of the calibration factors to be applied to the Aloka TGS-113 GM survey meter was verified (1) by the measurement for contaminated soil samples removed from the crippled plant site and (2) the environmental field survey at Fukushima city. The calibration factor of $4.8(=2.4 \times 2.0) \mathrm{nSv} / \mathrm{h}$ per $\mathrm{cpm}$ determined for the TGS-series end-window GM probes will be useful in converting the readings to rough estimates of the external beta (skin) dose received during the emergency radiological monitoring following the accident.

\section{Acknowledgements}

The authors wish to thank Mr. T. Fujisaku for his assistance in the field work at Fukushima city. 


\section{References}

[1] NCRP, Calibration of survey instruments used in radiation protection for the assessment of ionizing radiation fields and radioactive surface contamination, NCRP report No. 112 (1991).

[2] R. L. Coleman, Beta dose rate evaluations with a Geiger-Mueller pancake detector, University of Tennessee, Master's thesis, (1993).

[3] J. S. Durham, VARSKIN 3: A computer code for assessing skin dose from skin dose contamination,
NUREG/CR-6918, U.S. Nuclear Regulatory Commission, (2006).

[4] N. Tsujimura, T. Yoshida and S. Furuta, Measurements and calculations of beta dose rates on contaminated ground at the Fukushima Daiichi nuclear power plant site, Proc. IRPA-13, May 13-18, 2012, Glasgow, UK, (2012). Available at http://www.irpa13glasgow.com/information/downl oads/, (File name: P12.09.doc). 